\title{
Somos Mexicanos, no Somos Negros: Educar para Visibilizar el Racismo “Anti-Negro”
}

\section{We are Mexicans, We are not Blacks: Educating to Make “Anti- Black” Racism Visible}

\author{
Rodrigo Zárate * \\ Universidad Veracruzana
}

\begin{abstract}
Este artículo describe los resultados de un proceso paralelo de formación e investigación. Analiza de qué modo se puede diseñar e implementar un currículum que visibilice la precariedad del acceso a la justicia social como reconocimiento que experimentan los sujetos afrodescendientes y nombre el racismo que moldea los imaginarios de estudiantes universitarios. Expone cómo se reproduce la idea de que "en México no hay negros" con base en el currículum promovido por el Estado y algunas formas en que los sujetos experimentan dicha invisibilización. Su principal aporte es articular la Investigación basada en las artes, la Teoría crítica de la raza, la Educación intercultural y la Educación para los medios, en un proceso de investigación educativa dialógico que construye un currículum crítico para visibilizar la reproducción del racismo y la exclusión que propicia.
\end{abstract}

Descriptores: Educación intercultural, Justicia social, Investigación participativa, Alfabetización informacional, Educación ciudadana.

This article describes the results of a parallel training and research process. It analyzes how a curriculum can be designed and implemented to highlight the precariousness of access to social recognition of Afro-descendant individuals and name the racism that shapes the imaginary of university students. It explains how the idea that "there are no blacks in Mexico" is reproduced based on the curriculum promoted by the State and describes some ways in which the subjects experience the lack of recognition. Its main contribution is to articulate arts-based research, critical race theory, intercultural education and media education, in a process of dialogical educational research that builds a critical curriculum to make visible the reproduction of racism and exclusion.

Keywords: Intercultural education, Social justice, Participatory research, Information literacy, Civic education. 


\section{Introducción a “un país sin negros”}

La Constitución política de México reconoce la igualdad de todos los ciudadanos y prohíbe toda forma de discriminación "que atente contra la dignidad humana y tenga por objeto anular o menoscabar los derechos y libertades de las personas"; sin embargo, durante más de doscientos años de historia nacional varios grupos sociales con características determinadas han experimentado condiciones de privilegio o de desventaja en el reconocimiento social a su dignidad.

$\mathrm{Y}$ en ese contexto de desigualdad, uno de los grupos que han enfrentado y enfrentan mayores desventajas es el que integran aquellos sujetos identificados como "negros". Empezando por la desventaja que supone el hecho de que, a diferencia de los pueblos originarios, los pueblos afrodescendientes no han sido reconocidos constitucionalmente como "sustento original" de la composición pluricultural de la nación; a pesar de haber registros de su presencia en este territorio desde antes de que se constituyera como un país independiente.

De modo sistemático y consistente a través del tiempo, la pedagogía nacionalista del Estado ha construido como inexistente la afrodescendencia en el territorio nacional, y se ha limitado a señalar la presencia de esclavos africanos en los procesos de conquista y colonización emprendidos por españoles en América. Ha reproducido el mito fundacional del mestizaje eugenésico entre españoles e indígenas; de tal suerte que, al mismo tiempo que ha ensalzado al "mestizo" como esencia indiscutible de la identidad nacional, ha construido al "negro" como el esclavo primitivo que alguna vez existió y "desapareció sin dejar huella" cuando terminó formalmente el dominio colonial.

El proyecto educativo oficial ha sido cimentado sobre un imaginario social (Castoriadis, 2013) que de forma paralela naturaliza el vínculo de lo europeo/occidental con la civilización, la modernidad, el progreso y la evolución; y el vínculo de "lo indígena" y "lo africano" con la falta de civilización, el primitivismo, el atraso y la involución. Por lo cual, desdibuja de la historia a quienes asume irredimibles y exalta con orgullo la redención de sujetos defectuosos e indeseables por medio del mestizaje; instituyendo así un imaginario de nación y un modelo de identidad nacional que prácticamente no establece ningún vínculo identitario con pueblos africanos.

De ese modo, la educación mestizófila ha contribuido a que, aun cuando miles de sujetos africanos y sus descendientes estuvieron presentes en este territorio antes de que fuera un país independiente, comúnmente se les considere a los "negros" una minoría extranjera y haya "un profundo desconocimiento" sobre su presencia y participación en la historia y presente de México (Masferrer, 2011, p. 150). Ha contribuido a construir un imaginario de país "sin negros", a pesar de que, en 2015 y en el marco del Decenio Internacional para los Afrodescendientes promovido por la Organización de las Naciones Unidas (ONU), una encuesta realizada por el Instituto Nacional de Estadística y Geografía (INEGI) reveló que 1.4 millones de mexicanos (el 1,2\% de la población nacional) se reconocen como afrodescendientes ${ }^{1}$.

\footnotetext{
${ }^{1}$ También resulta significativo que haya tomado casi doscientos años de vida nacional, que se realizara un estudio desde el poder del Estado para conocer qué porcentaje de la población nacional se reconoce "afrodescendiente", y que antes de eso la única diferencia étnica que se reconocía y documentaba era la de los pueblos originarios.
} 
Por lo anterior, con este artículo busco responder ¿qué origina la invisibilización sistemática de los "negros" promovida por la educación pública en México? Y ¿qué estrategias pedagógicas y de investigación educativa pueden desarrollarse para visibilizar su historia, su presente y las causas que los marginan del reconocimiento social? Así, en los siguientes apartados describiré, cómo se fundamentan teóricamente un currículum racista y uno anti-racista, cómo se relacionan los sujetos con el racismo, las estrategias metodológicas empleadas en el proceso de investigación y los resultados construidos en colaboración con un grupo de estudiantes universitarios, para finalmente exponer mis reflexiones en torno a cómo visibilizar y nombrar el racismo "anti-negro" en el aula, y a cómo fortalecer las identidades afrodescendientes.

\section{La construcción de un currículum racista}

En un Estado nacional como el mexicano, la narrativa del poder sobre la identidad nacional, refleja en gran medida la perspectiva del mundo desde la que, en un momento histórico-social concreto, piensan y actúan los grupos sociales privilegiados. Describe lo que asumen como propio y ajeno, destaca las características que definen su unicidad con respecto a los Otros diferentes; y en forma de textos, imágenes, sonidos, espacios arquitectónicos y obras escultóricas, construye las fronteras entre el "nosotros nacional" y el "ellos extranjero". Además, reproduce una determinada gramática de identidad/alteridad, una forma particular de entender y estructurar las interacciones sociales en la diversidad (Gingrich, 2004).

En México, como en prácticamente toda América Latina, los grupos sociales privilegiados nunca han sido miembros de los pueblos originarios o afrodescendientes, sino descendientes de las élites mestizas y criollas que emprendieron la lucha de Independencia en el siglo XIX. Es decir, quienes han construido "un país sin negros", lo han hecho desde una tradición de pensamiento occidental, eurocéntrica y capitalista; desde un imaginario social heredero en cierta medida, de la visión del mundo de los conquistadores, para quienes los "negros" eran bestias sin inteligencia y, por tanto, sin alma. De tal suerte que en un orden de colonialismo interno (González Casanova, 2003), las narrativas sobre la identidad nacional que han desarrollado a través del tiempo, han sido moldeadas en mayor o menor medida, por ideas e imágenes racistas acerca de sí mismos y de los Otros diferentes.

Su imaginario ha incorporado y reproducido un sistema de pensamiento racista que valora positiva o negativamente la apariencia y/o las características culturales de sujetos y grupos, y los ubica jerárquicamente como superiores o inferiores (Grosfoguel, 2011); con el objeto de mantener o exacerbar la desigualdad de oportunidades en su acceso a la justicia social (Berman y Paradies, 2008). Además de reproducir una "política identitaria" colonial que privilegia "la belleza, el conocimiento, las tradiciones, espiritualidades y cosmologías masculina, cristiana y occidental”, al mismo tiempo que construye como "inferiores y subalternas la belleza, el conocimiento, las tradiciones, espiritualidades y cosmologías no cristianas y no occidentales" (Grosfoguel, 2011, p. 345); es decir, que reproduce una gramática de identidad/alteridad racista.

Aunque obviamente, las narrativas sobre la identidad y la alteridad promovidas desde el poder, suelen ser políticamente correctas y no expresan ideas racistas de forma explícita. De tal suerte que, el racismo "anti-negro" se manifiesta en los discursos del Estado, 
principalmente marginando a los pueblos afrodescendientes del reconocimiento social a su participación en la historia y en el presente nacionales, construyendo a los esclavos africanos exclusivamente como integrantes del estrato social de más baja categoría en la sociedad colonial de castas, y omitiendo ensalzar con dignidad la identidad "negra" de mexicanos notables.

Mientras que, desde el poder económico de los medios de comunicación, por ejemplo, el racismo "anti-negro" puede expresarse de forma sutil construyendo la afrodescendencia nacional como inexistente por medio de lo que podemos llamar "eugenesia narrativa", o bien representando a los sujetos "negros" de modo recurrente cómo primitivos caníbales y/o tontos en narrativas cómicas que los ridiculizan. Y un claro ejemplo de lo segundo es que, en el marco de la cobertura televisiva del mundial de fútbol de Sudáfrica en 2010, detrás de los presentadores "blancos" del programa Primero Noticias (Televisa), aparecían actores igualmente "blancos" con la cara pintada de negro, pelucas "afro", vestidos con imitaciones de pieles de animales y agitando lanzas (Velázquez, 2010).

Por otra parte, si sus prácticas son calificadas como racistas desde el activismo y la academia, desde el poder se niega sistemáticamente que lo sean. Por ejemplo, no se asume como una práctica racista que la ideología mestizófila prescriba la "blancura occidental" como referente de progreso, y la "negritud" como señal de atraso. Por lo tanto, desde la cultura dominante no se tiende a reconocer al racismo como un fenómeno que exista dentro de nuestras fronteras nacionales, y socialmente no es un concepto de uso amplio, se privilegia en cambio el uso del concepto "discriminación” y se emplea exclusivamente para describir acciones racistas explícitas.

La idea de que "en México no hay negros" en combinación con el hecho de que el concepto "racismo" sea entendido casi como marca registrada del contexto estadunidense, contribuye a ocultar el racismo "anti-negro" en nuestro país; pues se decide olvidar que "hay tantos racismos como grupos que tienen la necesidad de justificarse por existir como existen" (Bourdieu, 1990, p. 201), que el racismo adquiere múltiples formas dependiendo el contexto histórico-social en el que emerge y no se reduce a las expresiones exacerbadas del Klu Klux Klan que hemos visto representadas en el cine y la televisión.

Por lo anterior, considerando que la educación pública no es culturalmente neutral, sino que se construye desde el imaginario social que he intentado describir líneas arriba, el currículum (Gimeno, 1998) que dota de contenido y define la práctica del sistema educativo nacional reproduce en cierta medida una visión racista de la diversidad humana. Desde la visión del mundo legitimada por las élites contribuye a naturalizar la idea de que México es "un país sin negros" y que los únicos "negros" que han existido en este territorio fueron los esclavos de conquistadores y colonos españoles.

\section{Los sujetos frente al racismo}

Ahora bien, en un contexto como el mexicano donde las relaciones socioeconómicas de los sujetos son estructuradas en un orden de colonialismo interno, el racismo y la colonialidad insertos en el imaginario de nación facilitan la incidencia de procesos de discriminación social (Giménez, 2007); es decir, prácticas condicionadas culturalmente que buscan vulnerar los derechos de sujetos o grupos asumidos despreciables e indignos de reconocimiento. Prácticas cotidianas, interpersonales y/o estructurales, que se 
traducen en comportamientos hostiles y en accesos precarios a la justicia social para los sujetos dominados; y ocurren cuando sujetos y grupos en posiciones dominantes, imponen una definición sobrevaluada de sí mismos y definiciones "devaluadas y frecuentemente estigmatizadas" de los dominados.

Prácticas que se fundamentan en tres resortes complementarios: el etnocentrismo, el prejuicio inferiorizante y la intolerancia. El primero, actúa como impulso inconsciente que lleva a sujetos y grupos a considerarse a sí mismos mejores o más importantes que los otros diferentes, con base en exaltar positivamente alguno, algunos o el conjunto de sus atributos identificadores. El segundo, opera como preconcepción estereotípica que devalúa la dignidad y el reconocimiento de sujetos y grupos Otros en relación con los sujetos y grupos dominantes. Y el tercero, funciona como actitud de rechazo a la diferencia cultural de un grupo dominado, con base en considerar que sus creencias y prácticas constituyen una amenaza para los intereses materiales y simbólicos del grupo dominante, así como para la reproducción de su cultura y su hegemonía.

En consecuencia, los sujetos discriminados son "etiquetados" conceptualmente, "marcados" por categorías que les prescriben y justifican el trato que los demás les dispensan; y si interiorizan las ideas e imágenes racistas que motivan las acciones discriminatorias, pueden alterar la concepción que tienen de sí mismos y de su destino, hasta llegar a "convertirse en el tipo de persona que la etiqueta asignada había predicho" (Giménez, 2007, p. 49). Aunque también pueden desarrollar la capacidad de analizar críticamente sus experiencias de vida, sus interacciones y las narrativas con las que construyen sus identidades; y en tanto agentes, resistirse a que las prácticas discriminatorias de las que son objeto minen la confianza en sí mismos, y afirmar con dignidad sus identidades.

\section{La construcción de un currículum antirracista}

Por otra parte, si la pedagogía racista contribuye a exacerbar las desigualdades en el acceso a la justicia social y a estructurar relaciones sociales de dominación en la diversidad, en oposición, la pedagogía antirracista (Berman y Paradies, 2008) apuesta por conseguir lo contrario: la construcción de una sociedad que garantice el acceso equitativo de todo sujeto a la justicia social y desarrolle relaciones sociales de solidaridad en la diversidad; pues surge al reconocer que la cohesión social en la diversidad es improbable si no se combaten los sistemas de pensamiento y las prácticas que reproducen las desigualdades.

Como práctica político-pedagógica, el fin último del antirracismo es generar cambios sociales, a nivel individual y estructural, que lleven a garantizar el acceso a la justicia social de sujetos y grupos diversos. Por lo cual, el objetivo principal del currículum antirracista es visibilizar cómo se manifiesta y cómo se reproduce el racismo en el contexto histórico-social concreto donde se pretende actuar, y ofrecer las herramientas conceptuales y metodológicas para que los sujetos construyan miradas críticas y reflexivas en torno a las políticas y prácticas institucionales que reproducen el racismo.

En consecuencia, desde un posicionamiento democrático radical (Mouffe y Laclau, 1987), busca establecer relaciones sociales basadas en el reconocimiento a la dignidad de todo sujeto en la diversidad y, por ende, en la solidaridad. Apuesta por legitimar la perspectiva de quienes ocupan posiciones subalternas en la estructura social, la 
perspectiva de los sujetos y pueblos marginados de la justicia social. Además, busca que los miembros de grupos sociales dominantes "descubran el racismo estructural que se encubre en las decisiones de política económica y social y en la forma de operar de las instituciones públicas y privadas" (Schmelkes, 2013, p. 9); y actúen para erradicarlo, al menos en su contexto inmediato.

Desde la perspectiva filosófica del humanismo plural, asume la hibridación de toda cultura y el hecho de que muchas de las representaciones que tenemos de los Otros están "viciadas por un vínculo o implicación con el poder. Reconoce la dignidad humana de todo sujeto en la diversidad. Además, visibiliza y valora positivamente relatos Otros, pues busca romper con "la idea monolítica de lo humano, que sospechosa y peligrosamente, siempre coincide con el imaginario y cosmovisión de las comunidades hegemónicas occidentales" (Díaz, 2011, p. 78-79); es decir, reconoce y legitima el valor de la pluralidad en oposición a la dominación de visiones etnocentristas.

Desde la teoría crítica de la raza (Dunbar, 2008; Gillborn, 2006), asume que en el contexto "mexicano", las ideas racistas no son una desviación excepcional de los valores que norman la sociedad, sino parte fundamental de la cultura que les da forma; y que el modo en el que estructuran las relaciones sociales parece natural e inevitable para los miembros de la sociedad. Por lo cual, reconoce la experiencia de los sujetos dominados desde el racismo y la colonialidad como evidencia para cuestionar la legitimidad del orden social vigente.

Como experiencia de educación popular (Freire, 2011), busca crear espacios situados de formación y experiencias de aprendizaje que detonen procesos de introspección crítica; de de-construcción y re-significación de imaginarios e identidades. Para facilitar de ese modo, que los sujetos transformen la realidad que los subyuga por medio de su problematización, así como para guiarlos a descubrir que en su forma de ver el mundo "alojan" al opresor y los lleva a mantener su existencia "en una condición deshumanizante".

Y asumiendo que las ideas e imágenes racistas se reproducen de modo especialmente eficaz en forma de narrativas, adopta también la plataforma conceptual y metodológica de la Educación para los medios, en particular, la perspectiva "transformadora" propuesta por Kellner y Share (2005, 2006, 2007); la cual se fundamenta en cuestionar sistemáticamente la cultura de los medios de comunicación y de las industrias culturales desde múltiples perspectivas, poniendo un énfasis especial en inequidades de clase, etnicidad, género, sexualidad y poder.

Así, desde esa plataforma conceptual, el currículum antirracista crea las condiciones necesarias para que los estudiantes desarrollen procesos de de-construcción y resignificación de las categorías sociales desde las cuales construyen las identidades propias y las ajenas. Facilita que desarrollen lecturas subversivas al analizar representaciones de sujetos "negros", que las diseccionen buscando "fenómenos marginales, anteriormente reprimidos por un discurso hegemónico", que identifiquen cómo se articulan y pueden articularse los componentes de una determinada representación para producir diferentes tipos de significados (Krieger, 200, p. 184); y que rompan con la lógica interpretativa dominante "sedimentada" y naturalizada (Molina, 2013, 50). Es decir, contribuye a cuestionar la legitimidad de imaginarios sociales racistas y a facilitar la construcción de imaginarios que garanticen el acceso a la justicia social como reconocimiento a la dignidad humana en la diversidad. 


\section{Estudiar la implementación de un currículum antirracista}

Como docente e investigador, asumo que, en tanto sujeto, dispongo de capacidades de agencia para concebir y desarrollar formas novedosas de actuar en el mundo, y que la libertad de cátedra en el ámbito universitario ofrece cierto margen de acción para desarrollar innovaciones curriculares. Por ello, entiendo también que el aula opera como un espacio de innovación cuando los participantes en las experiencias formativas, incluidos los facilitadores, reflexionan críticamente acerca de cómo desarrollan sus procesos de construcción de conocimientos, con el objetivo de perfeccionar el currículum (Domínguez, Medina y Sánchez, 2011).

Por lo anterior y reconociendo en mi propia experiencia laboral ${ }^{2}$ un recurso para desarrollar la investigación, adopté la propuesta metodológica de la Investigación basada en las artes (Hernández, 2008), desde la cual, por medio del análisis colectivo y/o la creación de narrativas audiovisuales, se desarrollan diálogos amplios y profundos acerca de los fenómenos concretos a los que se dirija el interés del estudio. En este caso, conocer y valorar maneras diversas de representar a los sujetos "negros", destacando matices y lugares no explorados, visibilizando aquello de lo que comúnmente no se habla, aquello que suele darse por hecho y que se naturaliza.

Primeramente, como estrategia metodológica para desarrollar la construcción de conocimientos, implementé un proceso de formación/investigación en torno a un taller de cine documental, diseñado con base en el currículum antirracista descrito en el apartado anterior. El taller se denominó "Documentar la diversidad" y para reunir al grupo de estudio fue ofrecido de forma gratuita a estudiantes de licenciatura de la Universidad Veracruzana ${ }^{3}$, en su campus de Xalapa durante el semestre febrero-junio de 2015.

Para seleccionar al grupo de estudio entrevisté a 43 aspirantes. Les informé que su participación en el taller implicaba participar en la investigación referida y todos accedieron; además para orientar el proceso de selección, llenaron un cuestionario que tenía por objeto conocer sus datos generales (edad, género, licenciatura, semestre), su nivel socioeconómico, su origen geográfico, étnico y orientación sexual, así como la disponibilidad de horarios para asistir al taller. Finalmente, de los 43 estudiantes entrevistados (matriculados en 23 programas de licenciatura diferentes), fueron admitidos 20 (matriculados en 13 programas diferentes de las 6 áreas académicas en las que administrativamente se divide la Universidad Veracruzana: Artes, Ciencias biológico agropecuarias, Ciencias de la salud, Económico administrativas, Humanidades y Técnica), tratando de que el grupo representara la mayor diversidad posible con respecto a su género, orientación sexual, origen étnico y geográfico, nivel socioeconómico y la licenciatura cursada.

Habiendo creado un escenario para desarrollar la construcción de conocimientos, desarrollé un proceso de investigación cualitativo fundamentado en el paradigma

\footnotetext{
${ }^{2}$ Me he desempeñado como realizador de documentales y docente en temas de creación audiovisual y apreciación cinematográfica, en México y en Suecia por más de quince años.

${ }^{3}$ Una de las universidades públicas con mayor matrícula en el sureste mexicano y presencia en cinco campus dentro del estado de Veracruz, en la región costera del Golfo de México.
} 
interpretativo, en particular en la perspectiva del interaccionismo simbólico (Blumer, 1986). De tal suerte que, asumiendo que lo individual es hasta cierto punto reflejo de lo colectivo, el objetivo metodológico fue analizar e interpretar procesos sociales de construcción simbólica y los significados que los sujetos atribuyen a sus constructos y sus acciones. En consecuencia, implementé un enfoque etnográfico (Rockwell, 2009) que permitiera visibilizar lo "no evidente" y "documentar lo no-documentado" por medio de entrevistas a profundidad y observación participante. Para posteriormente estudiar la información recogida desde el análisis crítico de discurso (Van Dijk, 2003), intentando realizar una "etnografía de los discursos" (Olmos, 2015).

Desde la perspectiva antirracista del estudio, implementé cuatro sesiones de grupo focal en las cuales los estudiantes analizaron representaciones diversas de sujetos "indígenas", "españoles/güeros", "negros" y "mestizos", visibilizando y contrastando las diferencias; con el objetivo de detonar su reflexión en torno a cómo se construye la identidad nacional desde el poder y el lugar que los afrodescendientes ocupan en esos relatos.

Cada una de ellas inició con una "lluvia de ideas" donde los estudiantes compartían en plenaria sus conocimientos acerca de la categoría abordada en cada caso. Posteriormente, yo les presentaba una selección de imágenes tomadas de Internet, tratando de ofrecerles una muestra de las representaciones recurrentes al respecto. Enseguida, en equipos de 4 o 5 estudiantes, dialogaban acerca de lo dicho en la "lluvia de ideas" y de sus impresiones acerca de las imágenes; para volver a un diálogo en plenaria acerca de las conclusiones a las que había llegado cada equipo. Y finalmente, analizaban colectivamente representaciones audiovisuales de la categoría estudiada; que en el caso del grupo focal sobre cómo se representa "lo negro", fue un cortometraje documental acerca de los pueblos afromexicanos de la Costa Chica del estado de Oaxaca".

De las cuatro sesiones de grupo focal hice un registro audiovisual, así como un registro escrito en notas de campo documentando mi proceso de observación participante como facilitador/investigador. Transcribí los diálogos en el aula y organicé los datos en tres diferentes categorías para describir cómo construían la identidad de los sujetos adscritos a las categorías de estudio: sus grupos de pertenencia, sus atributos identificadores y sus biografías (Giménez, 2009). Además, identifiqué las convergencias y divergencias en las construcciones que los estudiantes habían hecho de los sujetos "indígenas", "españoles/güeros”, “negros” y "mestizos”.

Por otra parte, para contrastar y complementar los testimonios que emergieron de los grupos focales y mis observaciones en campo, realicé también dos series de entrevistas a profundidad antes y después de las sesiones de grupo focal; y con base en toda la información recopilada, redacté una historia de vida de cada uno de los seis estudiantes que elegí como casos de especial interés, por su compromiso con el taller y la investigación, y por su trayectoria de vida particular.

Asumiendo que reconstruir sus biografías me permitiría identificar sus "percepciones, intereses, dudas, orientaciones, hitos y circunstancias que -desde su perspectiva- han influido significativamente en ser quienes son y en actuar como lo hacen" (Bolívar y Domingo, 2006, p. 6), el propósito fue analizar de qué manera se relacionan sus

\footnotetext{
${ }^{4}$ Documental realizado por la Universidad Nacional Autónoma de México (UNAM) que se encuentra disponible en la siguiente dirección electrónica: https://youtu.be/QygIji-rGbI
} 
experiencias individuales con los contextos histórico-sociales concretos en los que han desarrollado y desarrollan sus trayectorias vitales; en particular analizar de qué manera han contribuido sus experiencias de vida en los ámbitos familiar y escolar, a moldear sus imaginarios de la identidad y la alteridad en el marco de la nación.

Con toda la información recabada por medio de las transcripciones de los grupos focales y las entrevistas a profundidad, volví a identificar recurrencias, divergencias y relaciones desde la perspectiva del análisis crítico del discurso (Van Dijk, 2003). Además, de modo complementario y paralelo, para contextualizar las experiencias de los estudiantes en el marco de la historia nacional, hice una reconstrucción de cómo se ha reproducido la dominación colonial de la otredad en la nación.

Entonces, con el propósito de desarrollar un proceso de doble reflexividad (Dietz, 2011), expuse a los estudiantes los hallazgos del estudio y comentaron mi interpretación de los datos en dos nuevas sesiones de grupo focal, una enfocada en discutir las conclusiones acerca de cómo construyen las categorías de estudio y otra en reflexionar en torno al proceso mismo de enseñanza-aprendizaje. Finalmente, a partir de las conclusiones llevé a cabo los cambios acordados colectivamente y este artículo se fundamenta en la perspectiva que emergió del diálogo entre estudiantes-investigadores y facilitadorinvestigador en dichos talleres.

Y para darle forma al apartado siguiente, de toda la información generada recuperé testimonios de 9 estudiantes, extraídos de las entrevistas a profundidad (EP), de las sesiones de grupo focal (GF) y de los talleres de reflexividad (TR). Los testimonios de Claudia, estudiante de Publicidad y relaciones públicas y Antropología social; Flor, de Sociología; Héctor, de Lengua y literatura hispánica y autoadscrito como afrodescendiente; Irasema, de Fotografía; Jorge, de Ingeniería civil; Laura, de Fotografía; Olga, de Publicidad y relaciones públicas; Raquel, de Sociología y Tania, de Química farmacéutica biológica ${ }^{5}$.

\section{La construcción de los "negros" en el marco de la nación}

En relación con su pertenencia social, los estudiantes coinciden en construir a los negros como miembros de una raza. Otra y de una comunidad de esclavos. Por defecto los imaginan como miembros de una comunidad nacional extranjera (africana o estadunidense principalmente) o vinculados a ella por herencia. Al mismo tiempo, los conciben como miembros de un grupo minoritario y prácticamente invisible de la población nacional. Es decir, en la gramática de identidad/alteridad (Gingrich, 2004) dominante la identidad nacional no sólo no incluye a la identidad negra sino que naturalmente la excluye, pues según la historia oficial somos producto del mestizaje entre españoles e indígenas; lo cual sintetiza Olga al definir los límites de la identidad nacional: "somos mexicanos, no somos negros" (EP1/13032015).

Entre los atributos identificadores de los sujetos negros, coinciden en destacar en primer lugar sus rasgos fenotípicos, en particular su color de la piel: más morena de lo que la tiene cualquier persona que vive en México. Marcadores raciales que detonan procesos

${ }^{5}$ Para preservar el anonimato de los estudiantes acordé con ellos asignarles nombres ficticios. 
de discriminación social (Giménez, 2007) como otorgar un reconocimiento precario a la dignidad y valía del sujeto que los presenta; por lo cual, coinciden en señalar que socialmente, las características fenotípicas de los negros suelen ser percibidas como feas, e incluso, Raquel asume que son percibidas como el extremo opuesto del ideal de belleza occidental.

También coinciden en señalar que, desde una preconcepción estereotípica, la práctica de conductas moralmente reprobables $\mathrm{y} / \mathrm{o}$ criminales son asumidas como atributos identificadores de los sujetos negros. Por ello, de acuerdo con Olga, si aparece un personaje negro en una película o programa de televisión, su madre lo identifica inmediatamente como el villano del relato y naturaliza el vínculo negro-criminal al decir frases como: "yo sabía que él era malo porque era negro" (EP2/09062015). Además de asumir "que si va a Nueva York y se encuentra un negro ya valió todo (...) que si entras a una colonia de negros ya así dile bye a tu vida, van a vender tus órganos..." $(\mathrm{TR} / 28112015)$.

Por último, un grupo de estudiantes coincidió en destacar las características corporales de los sujetos como atributos identificadores de las identidades negras. Dos estudiantes describieron el cuerpo de la mujer negra como objeto de deseo sexual, caracterizado por tener curvas exuberantes y otros dos describieron el cuerpo del hombre negro definido por su gran musculatura y fortaleza física. Además, coincidieron en mencionar atributos identificadores culturales como la habilidad artística en la música y la danza; y un par de estudiantes recordó narrativas televisivas y cinematográficas que los representan vinculados con la práctica de rituales, hechicería y magia africana.

Por otra parte, en relación con su narrativa biográfica, coinciden en construir la historia de vida de los sujetos negros vinculada primeramente al esclavismo; lo cual puede explicar que, de acuerdo con Raquel, identificar la presencia de atributos fenotípicos afro en los sujetos, hace que el imaginario social nos lleve directamente a relacionarlos con los esclavos que llegaron de África entre los siglos XV y XIX. Además, de forma general, coinciden en pensar la historia de vida de los sujetos "negros" marcada por enfrentar múltiples desventajas, por ejemplo, ser objeto de prácticas diversas orientadas a limitar su acceso a la justicia social, destinatarios de prácticas discriminatorias que los despojan del reconocimiento a su dignidad y/o a su identidad como mexicanos.

En ese sentido, Raquel y Flor coincidieron en señalar que socialmente, identificar a un sujeto como negro es causal para tratarlo de otra manera, para inferiorizarlo y negarle el reconocimiento a su dignidad. Mientras Claudia los describió experimentando peores condiciones de vida y menor visibilidad que los “indígenas", e Irasema destacó que en los censos nacionales no son tomados en cuenta considerando su especificidad étnica; además, señaló que, en Oaxaca, cuando los sujetos afromexicanos dejan sus comunidades para ir a la ciudad, suelen ser confundidos por las autoridades migratorias con extranjeros centroamericanos.

Y en relación con la invisibilidad del pasado y presente afrodescendiente en México, es significativo que de todos los estudiantes que participaron en el estudio, ninguno recordó haber tenido nunca compañeros de clase afrodescendientes a lo largo de su trayectoria escolar, salvo Flor, que por vivir en Chetumal tuvo contacto con "negros" de Belice, y Raquel, en Colombia como estudiante de intercambio; además, de que ninguno de todos los participantes en el estudio, salvo David, identificó a Héctor como "negro". También es significativo que las fuentes de información primaria a partir de las cuales 
han dado forma a su imaginario de lo negro sean principalmente los libros escolares sobre la historia nacional y la producción cultural estadunidense que consumen por medio del cine, el internet y la televisión.

\title{
6. Héctor frente al racismo "anti-negro"
}

Héctor nació en el Puerto de Veracruz, ciudad que desde tiempos de la Conquista ha sido hogar de población afrodescendiente, y asume con orgullo ser negro; aunque a lo largo de su vida ${ }^{6}$ ha enfrentado múltiples desventajas justamente por su apariencia negra. Por ejemplo, de su educación primaria en Córdoba, una ciudad en la región central del estado de Veracruz, recuerda experimentar un racismo algo recalcitrante.

En su testimonio describe un proceso de discriminación social (Giménez, 2007) en el que, con base en una política de identidad colonial, unos sujetos hacen escarnio de su color de piel, tomando ese atributo de su identidad como pretexto para devaluar su dignidad. Recuerda que a sus compañeros "les calaba" que destacara académicamente y por ello se burlaban de él constantemente. Haciendo referencia a su color de piel le decían cosas como "tú no juegas y tú estás feo porque eres negro", "tú no porque eres como un frijol” (EP1/11032015).

\begin{abstract}
$\Upsilon$ en casa, cuando compartía con sus padres el racismo que enfrentaba por negro, ellos lo invitaban a no hacer caso; al tiempo que su padre se esmeraba en ofrecerle argumentos para estar orgulloso de ser negro y le hacía ver, por ejemplo, que solían destacar positivamente como los mejores atletas. Ideas que le resultaban útiles para "ponerlas como un escudo ante el mundo que te está diciendo otras cosas; como estrategia para resistir las manifestaciones cotidianas del racismo anti-negro.

Sin embargo, no siempre lograba evitar que los comportamientos hostiles le afectaran, por lo cual, habiendo interiorizado el desprecio por su color de piel, en una ocasión deseó dejar de ser negro y en su inocencia se bañó en talco junto con su hermana. Hasta que finalmente, asumió una actitud reivindicativa de su dignidad como afrodescendiente, al estilo de Malcom X en la lucha por los derechos civiles, pensando cosas como siempre nos han sobajado y es porque nosotros somos una raza superior, que chingón, soy negro y lo mejor es ser negro. (EP1/11032015).
\end{abstract}

Siendo adulto, recuerda haber experimentado discriminación social detonada por la preconcepción estereotípica que naturaliza el vínculo negro-criminal. De modo recurrente, al entrar a una tienda y ser notada su presencia, los empleados le imponían una identidad devaluada y estigmatizada. No reconocían su honorabilidad por defecto, por el contrario, asumían que su presencia podía derivar en un robo; por lo cual, "uno de las cajas se salía y me seguía por los pasillos" (EP1/11032015).

También recuerda haberse enfadado la primera vez que leyó a José Vasconcelos, uno de los ideólogos de la mestizofilia mexicana y fundador de la Secretaría de Educación Pública. En su discurso encontró articulados los tres resortes que sostienen los procesos de discriminación social. El etnocentrismo que lo llevaba a considerar su identidad mestiza superior a la de los negros, el prejuicio inferiorizante estigmatizando y devaluando su identidad; y la intolerancia, como rechazo absoluto a su diferencia por asumir que la reproducción de los negros amenazaba el proyecto mestizófilo de identidad nacional.

${ }^{6} \mathrm{Al}$ momento de participar en el taller de documental, en el primer semestre de 2015, Héctor tenía 24 años. 
Y en particular le molestó el desdén con el cual demeritaba Vasconcelos la contribución de los africanos y afrodescendientes en el desarrollo nacional; el hecho de que desdibujara su relevancia en la historia y los estigmatizara como holgazanes, aun cuando su fuerza de trabajo impulsó decididamente la prosperidad económica de las élites. En sus palabras:

Lo primero que dice 'qué chingón que vinieron los españoles porque vinieron a
traernos la cultura a los otros pueblos (...) entonces, creamos esta raza de bronce
chingona', y decía que los negros lo único que aportaron fue la bulla, la lujuria y la
hueva'. Y yo dije 'oye, no mames cabrón ¿̇cuál hueva? ¿quién crees que cortaba los
putos campos de azúcar? (...) ¿̇quién trabajo las minas en el norte? (...) y no se les
menciona en la historia'. Eso sí me encabrona (...) creo que el fondo del malestar es
'no me digan que aquí no existo (...) cuando aquí yo tengo historia, no soy un
producto de la nada'... (EP1/11032015)

Finalmente, recordó haberse enfrentado en innumerables ocasiones a que su identidad como mexicano fuera puesta en duda debido a sus atributos identificadores fenotípicos. En particular destacó que, al viajar por autobús foráneo de una ciudad a otra, le ha ocurrido de modo recurrente, que los agentes de migración le pidan su identificación para demostrar que es mexicano. Y que, a lo largo de su vida, ha sido común que, partiendo de asumirlo extranjero le pregunten ¿cuál es su origen? ¿De dónde viene? ¿De dónde es? Siendo lo más común que lo crean cubano y que incluso, "gente que es de Cuba también me ha dicho lo mismo (...) no pareces de acá, pareces de allá” (EP1/11032015).

\section{Nombrar el racismo en el aula}

Convertir el aula universitaria en un espacio de reflexión acerca de cómo construimos a los sujetos "negros" permitió revelar el profundo desconocimiento de los estudiantes en torno a las contribuciones de africanos y afrodescendientes en la construcción de la nación. Visibilizó la información escasa e imprecisa a la que han accedido a lo largo de sus trayectorias educativas. $\mathrm{Y}$ en ese sentido, es significativo que ni siquiera estudiantes de antropología o sociología recordaron haber participado antes en experiencias educativas en las cuales se reflexionara al respecto.

Los diálogos reflexivos facilitaron que los estudiantes centraran su atención y su capacidad de análisis en temas, situaciones y representaciones en torno a las que no habían reflexionado nunca antes, "cosas que pueden parecer como muy obvias" (Raquel/TR/28112015); y que examinaran sus propias configuraciones identitarias. Los llevaron a cuestionar estereotipos y a darse cuenta de qué manera ellos mismos, quizás sin quererlo, los reproducen; a volver evidente cómo "los reflejamos con nuestros actos y nuestras palabras" (Jorge/EP2, 18062015). Además, de contribuir a que agudizaran su sentido crítico al realizar sus prácticas cotidianas de consumo cultural y trasladaran los debates en el aula y sus reflexiones al respecto, a las conversaciones con sus amigos o familiares.

El currículum antirracista empleado contribuyó a visibilizar las gafas culturales desde las cuales miramos y nos impiden reconocer a sujetos mexicanos como afrodescendientes. Creó condiciones propicias para detonar procesos de de-construcción

${ }^{7}$ En México se usa la palabra "hueva” como sinónimo de pereza. 
y re-significación de las categorías negro y racismo, a partir del análisis de desigualdades en la representación simbólica de la diversidad humana. Y al respecto es significativo que los estudiantes se sorprendieran al conocer mis conclusiones del estudio en el taller de reflexividad: que su forma de construir a los sujetos negros reproduce un imaginario forjado desde sistemas de pensamiento racistas y coloniales.

También lo es su conclusión acerca de por qué les sorprendió pensar sus prácticas discursivas calificadas como racistas. Coincidieron en señalar que la categoría "racismo" no es de uso común en el discurso público mexicano porque "en México no hablamos de razas (...) hablamos de culturas, de pueblos" y la palabra "racismo" remite a "raza", por lo cual se emplea en cambio la palabra "discriminación" (Raquel/TR/28112015). Mientras Jorge y Laura coincidieron en que antes de su participación en el taller, creían que definir una situación como racista implicaba que hubiera una agresión física y ahora reconocen formas sutiles o invisibles de racismo en la vida cotidiana.

Finalmente, como resultado de un proceso educativo antirracista, es de gran relevancia el cuestionamiento hecho por Raquel acerca de la falta de reconocimiento de que son objeto las civilizaciones africanas en las narrativas históricas creadas y difundidas desde el poder; pues su reflexión nos recuerda que imaginar México como un país sin negros no es un accidente, sino el resultado esperado de un sistema de dominación que desdeña las culturas africanas.

... la historia siempre ha sido así, los esclavos que llegaron de África, y también
donde está el recuperar que fueron antes de ser esclavos (...) creo que tampoco le
reconocemos que ha dado Africa por el mundo (...) antes de ser esclavos, algo
fueron, o sea toda una civilización, toda una serie de cosas que no conocemos, y no
conocemos no porque no queramos sino porque ahí hay una forma de dominación
para que no sepamos quienes son, y creo que sigue haciendo que nos remitamos a esas
ideas del esclavo y de que tenemos la autoridad para tratarlos menos.
(EP2/23062015)

\section{Reflexiones finales}

Visibilizar y nombrar el racismo "anti-negro" en las aulas mexicanas implica en primer lugar analizar el contenido que se le asigna socialmente a las categorías negro y racismo, destacando cómo y en qué contextos se emplean. Asumiendo que no son monolíticas y en tanto construcciones sociales, adquieren sentidos diferentes dependiendo de los espacios en los que se haga uso de ellas. Para que el proceso de enseñanza-aprendizaje concluya dotando ambas categorías de significados situados en el contexto de los estudiantes; es decir, resignificando las concepciones monolíticas construidas con base en el consumo de productos culturales de origen norteamericano.

Por ello, es pertinente revisar la historia oficial de la nación señalando las omisiones y/o tergiversaciones del rol que jugaron los africanos (secuestrados y forzados a trabajar como esclavos) y sus descendientes en el desarrollo cultural, social y económico de este territorio. Analizar de qué manera son construidos los negros en general y los afromexicanos en particular, en las narrativas que circulan los medios de comunicación. Y destacar el hecho de que el racismo no es una marca registrada del contexto estadunidense; sino que, como conjunto de ideas e imágenes que construyen la superioridad e inferioridad de sujetos diferentes, dependiendo el contexto histórico social en el que se desarrolle se manifestará de formas diversas y no sólo cómo violencia física contra sujetos afroamericanos. 
Además, en un entorno social construido desde sistemas de pensamiento racistas y colonialistas, es altamente probable que la experiencia de vida de los sujetos afrodescendientes sea marcada por enfrentar procesos de discriminación social; por lo cual es pertinente reconocer sus testimonios como fuente para visibilizar el racismo al que se enfrentan, así como para construir un imaginario de país donde se reconozca la presencia de la población afrodescendiente. Es necesario desarrollar estrategias pedagógicas que contribuyan a construir relaciones sociales basadas en la empatía y la solidaridad, en ponerse en los zapatos del otro para reconocer la dignidad de los sujetos y sus identidades en la diversidad.

Para construir una educación democrática e inclusiva en la diversidad es imprescindible visibilizar y nombrar el racismo en el aula, así como otros sistemas de dominación como el sexismo, el clasismo o la homofobia, orientados a limitar el acceso equitativo a la justicia social. Es necesario reconocer que la ausencia de la afrodescendencia en la historia nacional no es casual, sino una construcción de casi doscientos años de edad; y como estrategia básica para visibilizar el racismo anti-negro será de gran utilidad fomentar el diálogo reflexivo de los estudiantes en torno a preguntarse, por ejemplo, ¿por qué creemos que en México no hay negros si 1,2\% de la población nacional se asume afrodescendiente? ¿Por qué se emplea como insulto la palabra negro? ¿Por qué es común quejarse de tener que trabajar como negro para vivir como blanco?

Por otra parte, desde una perspectiva socio-antropológica, estudiar la implementación del currículum resulta una rica fuente de información para analizar cómo se reproduce y manifiesta el racismo en el contexto de los estudiantes; pues facilitó: 1) detonar la reflexión de los sujetos en torno a su visión del mundo y su experiencia en relación con los temas abordados; 2) analizar cómo está configurada la gramática de identidad/alteridad desde la cual construyen la identidad nacional y las identidades que le dieron origen, así como la manera en la que construyen sus identidades desde dicha gramática; y 3) estudiar de qué manera sus imaginarios de lo propio y lo ajeno han sido moldeados desde el racismo y la colonialidad.

Finalmente, es pertinente señalar que el desarrollo de este tipo de investigaciones como iniciativa de un docente no es suficiente para transformar la realidad social, pues haría falta un esfuerzo conjunto de todo el sistema universitario para estar más cerca de lograrlo. Sin embargo, no deben escatimarse esfuerzos por pequeños que sean, pues la Universidad pública debe servir para construir el bien común, y eso implica entre otras cosas, impulsar procesos de investigación y de educación inclusiva que legitimen el reconocimiento social a la dignidad humana en la diversidad.

\section{Referencias}

Berman, G. y Paradies, Y. (2008). Racism, disadvantage and multiculturalism: Towards effective anti-racist praxis. Ethnic and Racial Studies, 33(2),1-19.

Bolívar, A. y Domingo, J. (2006). La investigación biográfica y narrativa en Iberoamérica: Campos de desarrollo y estado actual. Forum: Qualitative Social Research, 7(4), art. 12.

Bourdieu, P. (1990). Sociología y Cultura. México: Grijalbo - CONACULTA.

Blumer, H. (1986). Symbolic interactionism: Perspective and method. Berkeley, CA: University of California Press. 
Castoriadis, C. (2013). La institución imaginaria de la sociedad. Ciudad de México: Tusquets.

Díaz, E. (2011). Otro humanismo por articular. Andamios, Revista de Investigación Social, 8(16), 71 90.

Dietz, G. (2011). Hacia una etnografía doblemente reflexiva: Una propuesta desde la antropología de la interculturalidad. Revista de Antropología Iberoamericana, 6(1), 3-26. doi: 10.11156/aibr.060102e

Domínguez, M. C., Medina, A. y Sánchez, C. (2011). La innovación en el aula: Referente para el diseño y desarrollo curricular. Revista Perspectiva Educacional, 5o(1), 61-86.

Dunbar, C. (2008). Critical race theory and indigenous methodologies. En N. Denzin, Y. Lincoln y L. T. Smith (Coords.), Handbook of critical and indigenous methodologies (pp. 85-99). Los Angeles, CA: Sage. doi: 10.4135/9781483385686.n5

Freire, P. (2011). Pedagogía del oprimido. Ciudad de México: Siglo XXI.

Gillborn, D. (2006). Critical race theory and education: Racism and anti-racism in educational theory and praxis. Discourse: Studies in the Cultural Politics of Education, 27(1), 11-32. doi: 10.1080/01596300500510229

Giménez, G. (2007). Formas de discriminación en el marco de la lucha por el reconocimiento social. En O. Gall (Coord.), Racismo, mestizaje y modernidad: visiones desde latitudes diversas (pp. 37-61). Ciudad de México: UNAM.

Giménez, G. (2009). Identidades sociales. Ciudad de México: Consejo Nacional para la Cultura y las Artes.

Gimeno, J. (1998). Currículum: Una reflexión sobre la práctica. Madrid: Ediciones Morata.

Gingrich, A. (2004). Conceptualizing identities: Anthropological alternatives to essentializing difference and moralizing about othering. En G. Bauman y A. Gingrich (Eds.), Grammars of identity/alterity: A structural approach (pp. 45-68). Londres: Bregan.

González Casanova, P. (2003). Colonialismo interno: Una redefinición. Conceptos y fenómenos fundamentales de nuestro tiempo. Ciudad de México: UNAM.

Grosfoguel, R. (2011). Racismo epistémico, islamofobia epistémica y ciencias sociales coloniales. Tabula Rasa, 14, 341-355.

Hernández, F. (2008). La investigación basada en las artes. Propuestas para repensar la investigación en educación. Educatio Siglo XXI, 26, 85-118.

Kellner, D. y Share, J. (2005). Toward critical media literacy: Core concepts, debates, organizations, and policy. Discourse: Studies in the Cultural Politics if Education, 26(3), 369386. doi: 10.1080/01596300500200169

Kellner, D. y Share, J. (2006). Critical media literacy is not an option. Londres: Springer.

Kellner, D. y Share, J. (2007). Critical media literacy, democracy, and the reconstruction of education. En D. Macedo, D. y S. R. Steinberg (Eds.), Media literacy: A reader. Nueva York, NY: Peter Lang Publishing.

Krieger, P. (2004). La deconstrucción de Jacques Derrida (1930-2004). Anales del Instituto de Investigaciones Estéticas, 84, 179-188.

Masferrer, C. V. (2011). La enseñanza sobre los africanos y afrodescendientes en la educación primaria y secundaria de México. En UNESCO, Afrodescendencia. Aproximaciones contemporáneas de América Latina y el Caribe (pp. 150-157). Ciudad de México: Centro de Información de las Naciones Unidas para México, Cuba y República Dominicana-. UNESCO. 
Molina, N. (2013). Discusiones acerca de la resignificación y conceptos asociados. Revista MECEDUPAZ, 3, 1-24.

Mouffe, C. y Laclau, E. (1987). Hegemonía y estrategia socialista. Hacia una radicalización de la democracia. Madrid: Siglo XXI.

Olmos, A. (2015). Análisis crítico de discurso y etnografía: Una propuesta metodológica para el estudio de la alteridad con poblaciones migrantes. EMPIRIA. Revista de Metodología de Ciencias Sociales, 32, 103-128. doi: 10.5944/empiria.32.2015.15311

Rockwell, E. (2009). La experiencia etnográfica: Historia y cultura en los procesos educativos. Buenos Aires: Paidós.

Schmelkes, S. (2013). Educación para un México intercultural. Sinéctica, 40, 1-12.

Van Dijk, T. A. (2003). Racismo y discurso de las élites. Barcelona: Gedisa.

Velázquez, M. E. (2010). Racismo y discriminación en Televisa. Recuperado de http://redaccion.nexos.com.mx/?p=1799

\section{Breve CV del autor}

\section{Rodrigo Zárate}

Estudiante del Doctorado en Investigación Educativa de la Universidad Veracruzana y miembro de la Red de Investigación Interdisciplinaria sobre Identidades, Racismo y Xenofobia en América Latina (INTEGRA). Diplomado en Estudios Avanzados por la Universidad Autónoma de Madrid en Historia del cine. Cuenta con 10 años de experiencia como docente de apreciación y realización cinematográfica en la Universidad Veracruzana y desde 2012, es coordinador académico de la escuela de cine en línea El Foro. Cuenta también con quince años de experiencia como realizador audiovisual; y entre su trabajo destacan una trilogía de documentales cortos sobre procesos migratorios, realizada en Suecia entre 2003 y 2006, así como sus documentales de divulgación científica realizados en el Laboratorio Multimedia X-Balam de la Universidad Veracruzana. Su principal interés de investigación es la articulación de la Educación para los medios y la Educación intercultural para estudiar la reproducción del racismo y construir justicia social en la diversidad. ORCID ID: 0000-0002-3900-5250. Email: rodrigo.zarate.moedano@gmail.com 